\title{
Deposition and Tribology of Carbon and Boron Nitride Nanoperiod Multilayer Hard and Solid Lubricating Films
}

\author{
Shojiro Miyake ${ }^{1}$ and Mei Wang ${ }^{2}$ \\ ${ }^{1}$ Department of Innovative System Engineering, Nippon Institute of Technology, \\ Saitama \\ ${ }^{2}$ Department of Research and Development, OSG Corporation, Aichi \\ Japan
}

\section{Introduction}

In the tribology application of thin films, in order to improve wear resistance properties, super hard films composed of boron, carbon and nitrogen have attracted much attention in recent years as known boron, carbon and nitrogen are used as basic component elements (Enomoto. Miyake, 1994; Miyake, 1999; Miyake et al., 1994). As also, it is expected to realize the application of solid lubricant films which will be provided super low friction coefficients to improve the lubricant properties of surfaces.

More and more so-called solid lubricant films in stead of lubricant oil are expected to work under such extreme conditions as high-temperature and vacuum operations in which lubricant oil is unqualified to run. In these solid lubricant materials, the representatives are soft metals as $\mathrm{Au}$ and $\mathrm{Ag}$, crystallizing layered inorganic compounds as graphite, h-BN, $\mathrm{MoS}_{2}$ (molybdenum disulfide) and $\mathrm{WS}_{2}$ (tungsten disulfide) and polymers as PTFE (polytetrafluoroethylene) et al. (Enomoto \& Miyake, 1994). On the other hand, a wearresistant, not the conventional solid lubricant film, is desired to reduce atomic-scale wear and friction force fluctuation (Miyake et al., 1994; Miyake, 1994; Miyake et al., 1992). One candidate is carbonaceous films such as diamond and diamond like carbon films, which have wear-resistant and lubricating properties (Miyake et al., 1994; Miyake, 1994; Miyake \& Kaneko, 1992).

The volume module of a hypothetical material, $B-C_{3} \mathrm{~N}_{4}$, which is structurally analogous to $\beta$ $\mathrm{C}_{3} \mathrm{~N}_{4}$, may be larger than or equal to that of diamond (Liu \& Cohen, 1989). The hardness of this stoichiometric crystalline carbon nitride is expected to exceed that of diamond. Partially crystalline carbon nitride films have been deposited by reactive sputtering, and their structure and compositions have been investigated. In our previous studies, the use of an atomic force microscope enabled accurate evaluation of the effect of nitrogen inclusions on nanoindentation hardness and microwear (Miyake et al., 1994).

Research on the development of nanoperiod multilayer films has recently been carried out, to improve the film hardness. For example, hard multilayer films were deposited, and it was found that the hardness of these multilayer films was significantly improved compared with that of one monolayer of them. As a super hard film, the superlattice film laminated with 
thin layers by several nanometers was investigated. Concretely, superlattice films such as $\mathrm{CNx} / \mathrm{TiN}$ (Li et al., 1995) and TiN/AlN (Nakayama, 1997) were performed. In our studies, the $(\mathrm{CN} / \mathrm{BN}) \mathrm{n}$ multilayer film was proposed to deposit using boron nitride and carbon nitride layer by layer (Miyake et al., 1999) to form a novel superlattice film and its properties were investigated. The hardness enhancement mechanism of a superlattice film is based on the restriction of dislocation movement within and between layers in the superlattice film (Donohue et al., 1995). In our previous study, a nanoperiod (CN/BN)n multilayer film was deposited in order to improve its hardness (Miyake \& Sekine, 2000). The nanoindentation hardness and modulus of dissipation of a 4-nm-period multilayer film are the highest and the lowest among other multilayer films (Miyake, 2003). The dependence of atomic-order wear properties on sliding cycles indicates that the wear resistance increased at the interface between the $\mathrm{CN}$ and BN layers of the multilayer films (Miyake, 2003).

Generally, friction force is proportional to contact area A and shearing strength S, i.e. $\mathrm{F}=$ AS. Friction coefficient $\mu$ is defined as friction force $F$ divided by load $W$, i.e. $\mu=F / W=$ AS/W. Hardness is defined as $\mathrm{H}=\mathrm{W} / \mathrm{A}$. Therefore, $\mu=\mathrm{S} / \mathrm{H}$. i.e. the friction coefficient $\mu$ is approximately proportional to the ratio of shearing strength $\mathrm{S}$ to hardness $\mathrm{H}$ (Bowden et al., 2004). To develop new low-friction solid lubricant films, the hardness $\mathrm{H}$ must be increased and the shearing strength $S$ must be decreased, as shown in Fig. 1 (Miyake et al., 2004). Therefore, nanoperiod multilayer films composed of low-shearing-strength graphite and hexagonal boron nitride ( $\mathrm{h}-\mathrm{BN}$ ) that have solid lubricating properties, are expected to have a low friction coefficient because the hardness is increased due to the nanoperiod multilayered structure, while the shearing strength is decreased due to the inclusion of the low-shearing-strength C and BN layers (Miyake et al., 2004).
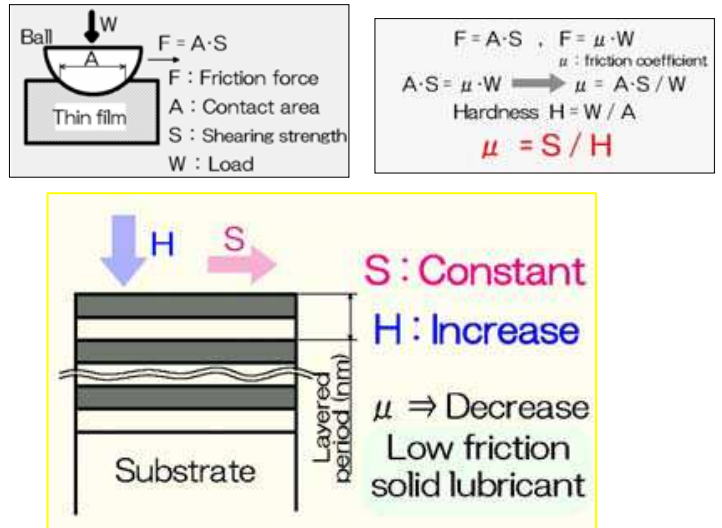

Fig. 1. Low-friction model of nanoperiod multilayer solid film: as the shearing strength $S$ is constant, $\mu$ decreases with an increase in hardness.

In this study, by utilizing the superlattice film technique above, the hard films were proposed to deposit and their hardness in perpendicular direction were significantly increased with increasing their elastic moduli. It is considered that the friction coefficient is decreased due to the effect of the hardness increases as keeping the shear resistance of a sliding plane paralleling its substrate. Our aim is focused on developing a new solid lubricant film with an extremely low friction which usual simple film and mixed film 
material lacked of carbon and boron nitride nanoperiod multilayer films were deposited by RF sputtering using two semicircular targets. Auger electron spectroscopy (AES), X-ray photoemission spectroscopy (XPS) and Fourier transform infrared spectrometer (FTIR) analysis were used to observe the coatings structure. Nanoindentation and microwear tests were carried out to investigate the nanometer-scale deformation properties, macroscopic friction coefficient and sliding endurance of these films.

\section{Experimental methods}

\subsection{Film deposition}

As shown in Fig. 2, films were deposited by a RF sputtering system, in which both targets and substrate were supplied with high frequency RF power. Then, two semicircular graphite and boron nitride sinters were used as targets, and they were fixed in the target holder. A film was deposited by rotating a substrate, and two kinds of the semicircular targets were set to alternately face the substrate in an Ar gas atmosphere as shown in Fig. 2. To deposit $\mathrm{C}$ and $\mathrm{BN}$ layers with the same thickness, the time of setting the substrate opposite to the graphite target was nearly twice that of the h-BN target.

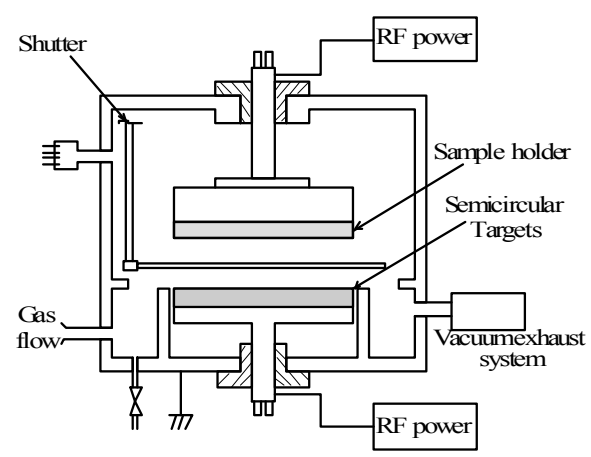

(a)
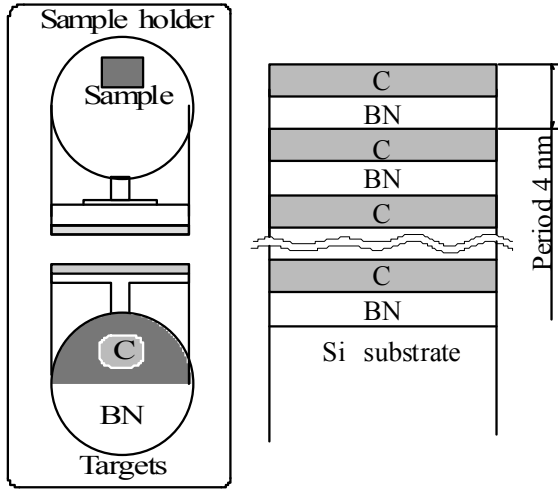

(b)

Fig. 2. Multilayer film deposition method of nanoperiod multilayer film using semicircular targets (a) and Model of 4-nm-period multilayer film

$\mathrm{A}(\mathrm{C} / \mathrm{BN}) \mathrm{n}$ film was deposited by rotating a substrate. The BN layer was deposited first, and then the carbon layer was deposited. The topmost of the $(\mathrm{C} / \mathrm{BN}) \mathrm{n}$ film was deposited to be a carbon layer. In this study, 2-, 4-, 6-, 8- and 10-nm-period multilayer films were deposited by controlling deposition time. To compare the multilayer $(\mathrm{C} / \mathrm{BN}) \mathrm{n}$ film with other films like as the 4-nm-period $(\mathrm{CN} / \mathrm{BN}) \mathrm{n}$ film, $\mathrm{C}$ (carbon) single-layer film, BN single-layer film and 4-nmperiod multilayer $(\mathrm{CN} / \mathrm{BN}) \mathrm{n}$ were prepared. The thickness of the $\mathrm{C}$ and $\mathrm{BN}$ single-layer films, $(\mathrm{CN} / \mathrm{BN}) \mathrm{n}$ and $(\mathrm{C} / \mathrm{BN}) \mathrm{n}$ multilayer films was proposed to be nearly $200 \mathrm{~nm}$. Before the deposition of a film, a substrate was pretreated by Ar sputtering in order to clean its surface.

\subsection{Tribology evaluation methods}

The micro Vickers hardness tester and nanoindentation experiment system with AFM (atomic force microscope) were employed to determine the hardness of the $(\mathrm{C} / \mathrm{BN}) \mathrm{n}$ 
multilayer, BN and C films. Micro-Vickers hardness was measured at a load of $0.05 \mathrm{~N}$ and the load duration of $10 \mathrm{~s}$. Nanoindentation test were performed at a maximum load of 100 $\mu N$. The hardness was geometrically calculated from the Ar section area of plastic deformation using the plastic deformation depth and $\mathrm{P}_{\max }$ maximum load. Plastic deformation depth was determined from the point of intersection of the straight line fitted to the appropriate unloading curve and the $\mathrm{x}$ axis to the point of the maximum deformation depth on $\mathrm{x}$ axis. The hardness $\mathrm{H}$ is evaluated from Eq. (1)

$$
\mathrm{H}=\mathrm{Pmax} / \mathrm{Ar}
$$

The nanoindentation hardness and surface deformation properties of the films were investigated using AFM (Digital instruments Nanoscope III) together with a nanoindentation measurement system (Hysitron Inc.). The nanoindentation hardness was measured by AFM with a Bercovich-type diamond indenter (a three-sided pyramid diamond tip) with a radius of about $100 \mathrm{~nm}$, under $20 \sim 25{ }^{\circ} \mathrm{C}$ temperature and $30 \sim 50 \%$ humidity conditions. The diamond tip is regularly checked using a quartz standard item. These films were as thin as $200 \mathrm{~nm}$, therefore, the nanoindentation hardness value evaluated under higher load was influenced by the substrate hardness. As a result, the hardness value of these films evaluated by this method under higher load is lower than that of real film. The test was performed with a loading time of $20 \mathrm{~s}$ at $60-100 \mu \mathrm{N}$ load. Here, the hardness is evaluated from the plastic deformation depth. The plastic deformation depth was evaluated from the intersection point of the $y$-axis and the straight line fitting from the appropriate unloading curve (Doerner \& Nix, 1986). In this study, the Vickers and nanoindentation hardness values of the silicon substrate were 1500 and $13 \mathrm{GPa}$, respectively.

To evaluate the deformation behavior using the nanoindentation test, energy analysis of the nanoindentaion curve was performed. Total deformation energy was calculated using the integral of the loading curve as shown in Fig. 3. The storage energy was calculated using the integral of the unloading curve. The dissipated energy was evaluated from the remainder of the total energy minus the storage energy. The modulus of dissipation was calculated by dividing the dissipated energy by the total energy (Donohue et al., 1995; Miyake et al., 2004; Miyake, 2005).

The hardness was evaluated from the plastic deformation depth which was determined from the point of intersection of the straight line fitted to the appropriate unloading curve and the $x$ axis (Doerner \& Nix, 1986; Syed Asif et al., 1999; Miyake \& Kim, 2003). The total deformation energy of nanoindentation was calculated as the integral of the loading curve. Storage energy was calculated as the integral of the unloading curve. As shown in Fig. 3, dissipated energy was evaluated as the total energy minus storage energy.

To clarify the tribological characteristic of an extremely thin film, an AFM with a diamond tip with a radius of about $50 \mathrm{~nm}$ was employed to observe the surface profile and microwear properties. A schematic representation of the evaluation is shown in Fig. 4. The oscillation scratch tests were performed with gradually increasing loads using the diamond tip indenter under setting conditions of a $6.7 \mu \mathrm{N} / \mathrm{s}$ loading speed, a $200 \mu \mathrm{N}$ maximum load. In addition, the oscillation scratch test was carried out to evaluate the fracture characteristics and adhesion strength of the film by measuring an acoustic emission (AE) signal which can indicate a critical load in the test.

Wear-resistance of the films was determined with a ball-on-disk tribometer opening under RT $\sim 400{ }^{\circ} \mathrm{C}$. As shown in Fig. 5, a disk specimen deposited a multilayer film was tested. 
The opposing stainless-steel ball (radius of $3.2 \mathrm{~mm}$ ) was slid against the specimen being set rotating. Friction force was measured by the strain gauge attached to the plane spring mounted the tribometer. Data on the friction coefficient were obtained without lubricant and a normal load of $9.8 \mathrm{~N}$, a sliding speed of $94 \mathrm{~mm} / \mathrm{s}$ and a room temperature of 25, 200 and $400{ }^{\circ} \mathrm{C}$, and a relative humidity of approximately $40 \sim 60 \%$. After the friction test, the wear tracts of the sample were observed by AFM and using an optical microscope and three-dimensional profile meter. The friction test was performed more than three times, and the mean and typical data were discussed. The variation of saturated friction value is less than $15 \%$.

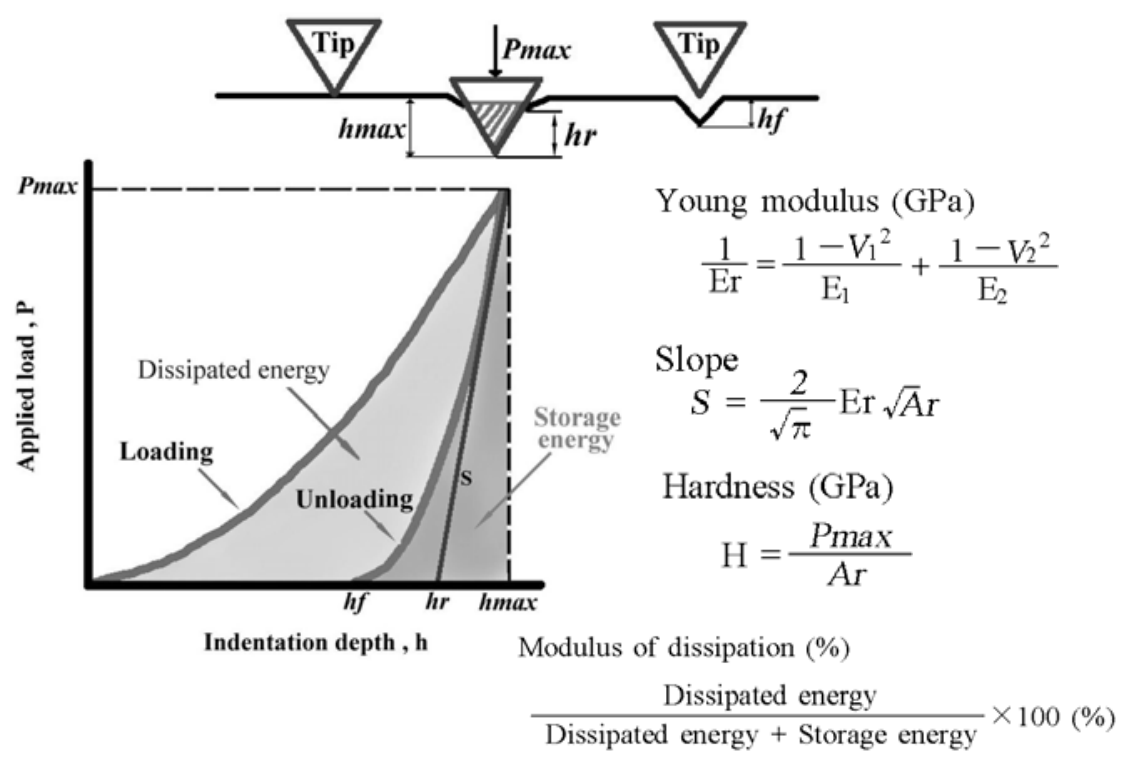

Fig. 3. Evaluation method of nanoindentation test

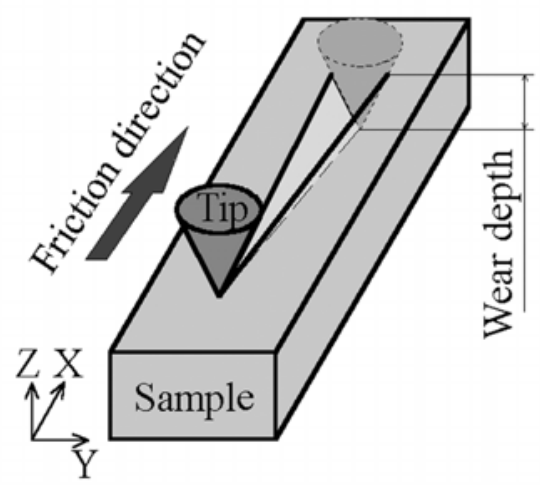

Fig. 4. Schematic representation of a load gradual increase nanoscratching test 


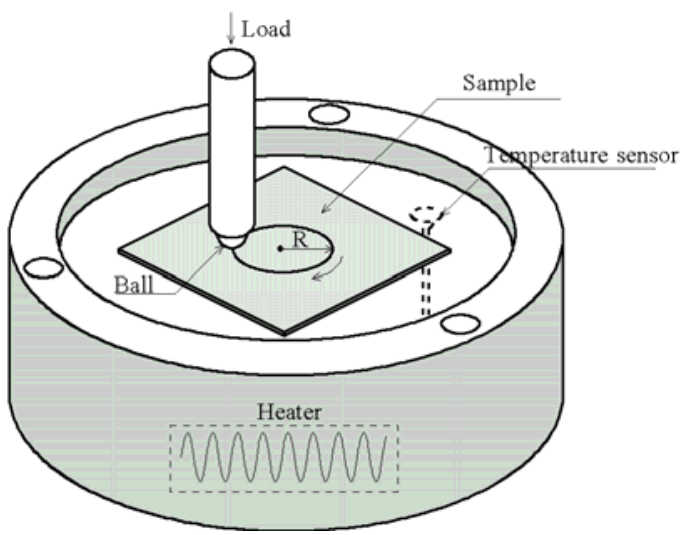

Fig. 5. High-temperature tribometer

\section{Results and discussion}

\subsection{Composition and structure of deposited films}

The total thicknesses of all the films tested were set at nearly $200 \mathrm{~nm}$. A crystalline structure cannot be detected by X-ray diffraction analysis, FTIR and TEM. These single-layer and multilayer films are found to be amorphous from these microanalyses (Miyake, 2005). From the Raman spectrum, the differences between these carbon-containing films were not clearly evaluated (Miyake, 2005).

In a previous paper, a transmission-electron microscopy (TEM) image of a nano-meterperiod multilayered film composed of alternate $\mathrm{C}-\mathrm{N}$ and $\mathrm{B}-\mathrm{N}$ layers was obtained and the structure of the period-layered $\mathrm{CN} / \mathrm{BN}$ was clarified. The thicknesses of both the C-N and B-C-N layers were controlled so as to be nearly identical. The period of this TEM image of the multilayer film is $8 \mathrm{~nm}$, therefore the thickness of each C-N and B-N layer is about $4 \mathrm{~nm}$. Even though the layers are very thin, each layer can be distinguished (Miyake, 2003). Moreover, atomic concentrations of boron, carbon and nitrogen elements classified as superhard film materials were detected according to Auger electron spectroscopy (AES) measurement of the depth profile of the multilayered films (Miyake et al., 2000). The C/BN multilayers discussed in this study were deposited by the same deposition method as that mentioned above. By controlling deposition time and using different targets, the $(\mathrm{C} / \mathrm{BN}) \mathrm{n}$ films were deposited as expected.

\subsection{Micro Vickers hardness and nanoindentation hardness}

The results of micro Vickers hardness of these thin films are shown in Fig. 6. The precise measurement could not be carried out for the BN simple layer film because there was some frictional peeling on the substrate after the test. Exactly as a expected effect of solid lubricant films, the micro Vickers hardness of $(\mathrm{C} / \mathrm{BN}) \mathrm{n}$ multilayer films synthesized in our study is changed with changing the multilayer period of the films. The hardness of the $4 \mathrm{~nm}$ $(\mathrm{C} / \mathrm{BN}) \mathrm{n}$ multilayer film shows the highest in all $(\mathrm{C} / \mathrm{BN}) \mathrm{n}$ films.

The nanoindentaion curves show a relationship between indenter penetration depth and load of these films obtained at $100 \mu \mathrm{m}$ as shown in Fig. 7. Therefore, the nanoindentaion hardness can be evaluated from the nanoindentaion curves and the results are shown in Fig. 
8. In the case of the BN film, as the indentation depth cased by an indenter was drastically fluctuated in the nanoindentation test, the result of the BN film in this test can not be reproducible. According to the indentation curves of the films, the maximum indentation depths of $\mathrm{C}$ simple film, 2- and 8-nm-period $(\mathrm{C} / \mathrm{BN})_{\mathrm{n}}$ films are quite similar and close to 15 $\mathrm{nm}$, and it can be confirmed that the plastic deformation depth is nearly $3 \mathrm{~nm}$. Upon the curves, it is observed that the deformation depth of the 4-nm-period $(\mathrm{C} / \mathrm{BN})_{\mathrm{n}}$ film shows a tendency to decrease significantly. The curve of indentation depth of the 4-nm-period $(\mathrm{C} / \mathrm{BN}) \mathrm{n}$ film is near that of the 4-nm-period $(\mathrm{CN} / \mathrm{BN})_{\mathrm{n}}$ film and shows the same tendency to decrease on its indentation depth. It is to say that elastic deformation mainly occurred on the surface of these multilayer films in the indentation test and the films exhibit excellent hardness. In particularly, the indentation hardness of the $4-n m-p e r i o d ~(C / B N)_{n}$ film is highest in all $(\mathrm{C} / \mathrm{BN})_{\mathrm{n}}$ films.

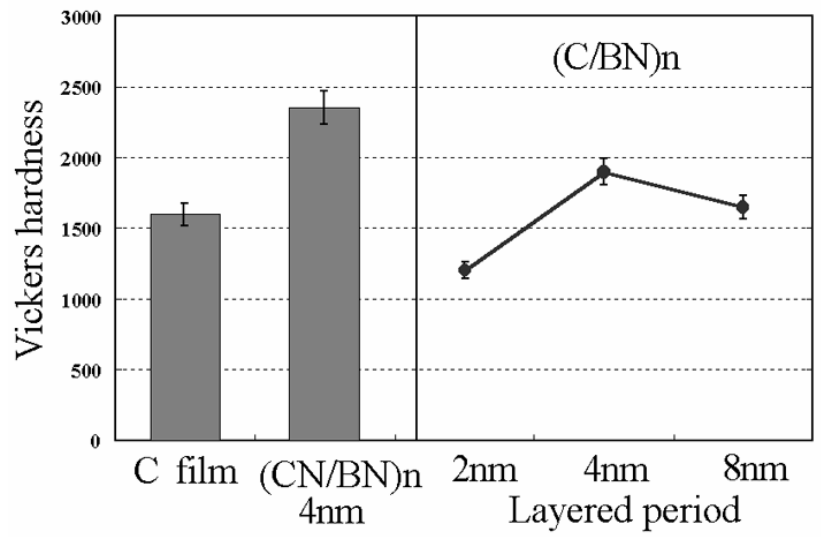

Fig. 6. Vickers hardness of super lattice films

When measuring the films in the micro Vickers test, the hardness could not be really measured by an indenter because the indenter would destroy those films and pierce through them, then reached the substrate of Si wafer. Hence, it was considered that the hardness of the film can not be exactly measured due to the influence of the substrate. In contrast, the hardness measurement will be hardly affected by the substrate employed as the groundwork in the nanoindentation test, because the indentation depth of the indenter is only about 3 to $17 \mathrm{~nm}$. Therefore, the hardness of these films could be really investigated and measured by the nanoindentation test. Upon the indentation test, it is obvious that the $(\mathrm{C} / \mathrm{BN})_{\mathrm{n}}$ multilayer film with a layer period of nearly $4 \mathrm{~nm}$ show the highest hardness.

Furthermore, the indentation hardness of $\mathrm{C}$ and $\mathrm{BN}$ monolayer and $(\mathrm{C} / \mathrm{BN}) \mathrm{n}$ multilayer films was evaluated and compared at maximum applied loads of 60, 80, and $100 \mu \mathrm{N}$. Compared with the elastic-plastic properties of the $(\mathrm{C} / \mathrm{BN}) \mathrm{n}$ multilayer films, the maximum indentation depth $\left(\mathrm{h}_{\max }\right)$ of the 4-nm-period multilayer film is less than that of the other films. The estimated average indentation hardness values in this study are summarized in Fig. 9. The hardness of all multilayer films is higher than that of the $\mathrm{C}$ and $\mathrm{BN}$ single layer films. It is observed that the nanoindentation hardness of the multilayer film changes with a change in a layer period. The multilayer film with the 4-nm-period film shows the highest hardness among all multilayer films in the study, indicating that the tribological properties 
of the multilayers, such as low friction coefficient and high wear-resistance, i.e. long wear life, were improved compared with those of the single layer (Miyake, 2005). Corresponding to this, the 4-nm-period film shows the highest hardness.

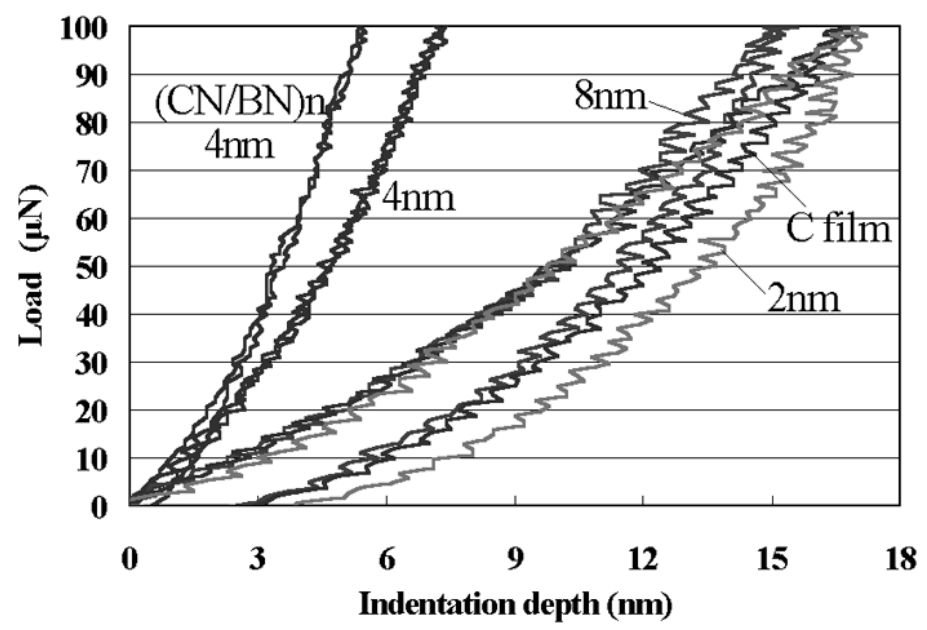

Fig. 7. Nanoindentation curves of 4-nm-period (CN/BN)n, 2-, 4- and 8-nm-period (C/BN)n super lattice films

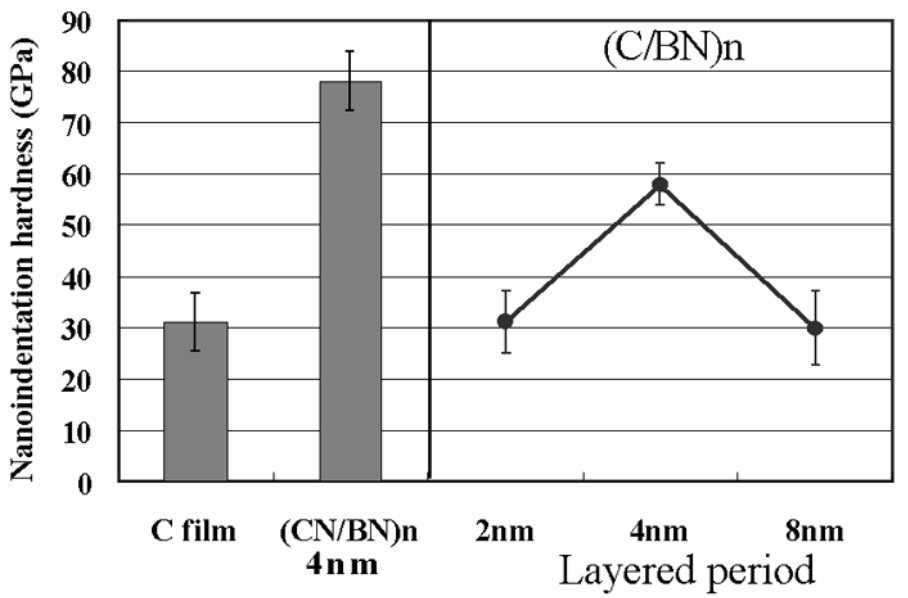

Fig. 8. Nanoindentation hardness of $\mathrm{C}$ film and $(\mathrm{CN} / \mathrm{BN}) \mathrm{n}$ and $(\mathrm{C} / \mathrm{BN}) \mathrm{n}$ super lattice films The relationship between the modulus of dissipation, nanoindentation hardness $(\mathrm{H})$ and the material factor of index of plasticity $(\mathrm{E} / \mathrm{H})$ for the monolayer and multilayer films is shown in Fig. 10. $\mathrm{E} / \mathrm{H}$ is a quantity value which is used to express the plastic deformation of material in the plastic index of material constant (Taniguchi, 1996). The modulus of dissipation and the $\mathrm{E} / \mathrm{H}$ decrease with an increase in nanoindentation hardness. The dissipated and storage energies of these films were evaluated. Compared with the single 
layer films, the total energy of the nanoperiod multilayer films decreased, and in particular, the dissipated energy of the multilayer films significantly decreased. Figure 10 shows the modulus of dissipation, which is calculated from the ratio of dissipated energy to total energy of the indentation. It is evident that the modulus of dissipation of the multilayer films was reduced to less than $50 \%$ due to the nanoperiod multilayer structure.

As shown in Fig. 10, the modulus of dissipation decreases with increasing hardness. It is considered that the deformation of multilayer films is mainly elastic deformation, along

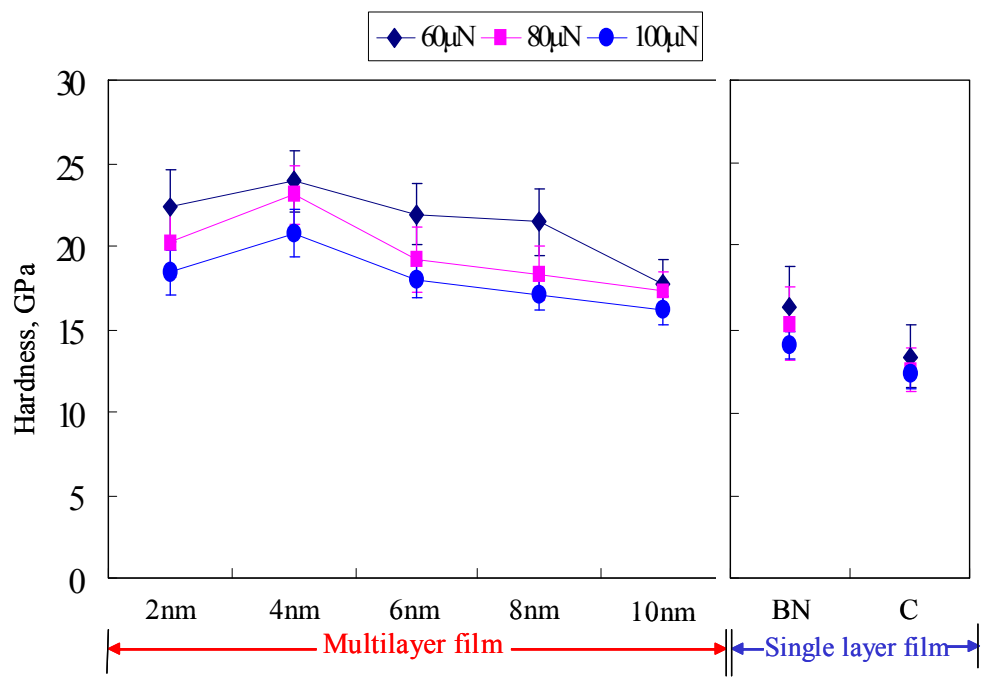

Fig. 9. Nanoindentaion hardness as a function of layer-periods for single layer and multilayer films (error bars: $3 \sigma$ )

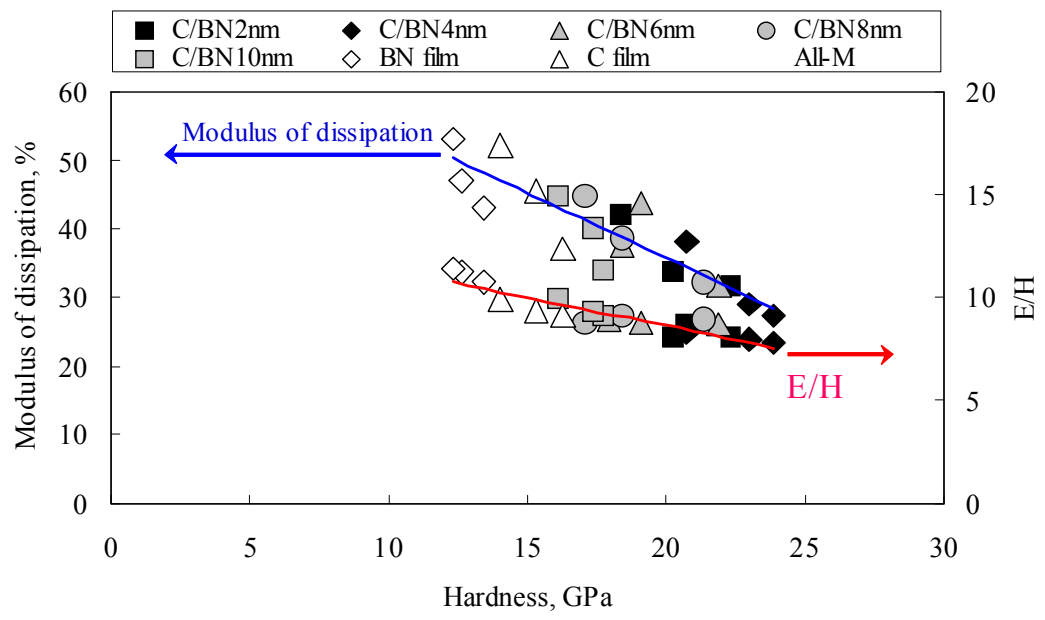

Fig. 10. Modulus of dissipation and the material factor of index of plasticity $(E / H)$ as a function of nanoindentation hardness for single layer and multilayer films 
with a low dissipation energy. The material factor of index of plasticity $(\mathrm{E} / \mathrm{H})$ was evaluated as Young's modulus E divided by hardness H (Miyake et al., 2004). The nanoindentation hardness is defined as the resistance to plastic deformation per unit area. On the other hand, the modulus of dissipation and $\mathrm{E} / \mathrm{H}$ corresponds to the ease of plastic deformation. By indentation testing, the hardest 4-nm-period multilayer film shows the lowest modulus of dissipation and $\mathrm{E} / \mathrm{H}$, i.e. it has less dissipated permanent deformation due to indentation. This is considered that the nucleation and propagation of the lateral cracks beneath the indentation were limited due to the nanostructure of the multilayer (Bhushan, 1995). Therefore, the relationship among nanoindentation hardness, the modulus of dissipation and $\mathrm{E} / \mathrm{H}$ was expressed approximately as a simple empirical formula for investigation and analysis of the nanoscale mechanical properties of film.

\subsection{Tribological properties}

The measured results of the frictional force and friction coefficient in the nano scratch test are shown in Fig.11. Upon the results, the frictional force of the BN film varies drastically and shows the highest value at the loads of 0 to $20 \mu \mathrm{N}$. It can be considered that the hardness of the BN film is lower than those of other films, therefore, the destruction on its surface easily occurred even from the beginning of the test and the frictional force of its surface shows to increase sharply. On the other hand, upon investigating the friction dependence of the $(\mathrm{C} / \mathrm{BN}) \mathrm{n}$ multilayer films on the period, it could be confirmed that the effect of the reduction in the frictional force of the $(\mathrm{C} / \mathrm{BN}) \mathrm{n}$ multilayer film with the period of $4 \mathrm{~nm}$ is significantly remarkable, and its hardness similarly exhibits a maximum value. With respect to the friction coefficients of these films, the initial values of the friction coefficients display drastically fluctuated, but they become steady with a load being over 40 $\mu N$. Upon the results, the friction coefficient of $B N$ simple layer film is as high as $\mu=0.45$ from $40 \mu \mathrm{N}$ load and those of 2- and 8-nm-period (C/BN)n films are $\mu=0.28$ and $\mu=0.24$, respectively. The friction coefficients of the carbon film and 4-nm period $(\mathrm{C} / \mathrm{BN}) \mathrm{n}$ film are as low as $\mu=0.22$ and $\mu=0.17$, respectively. It could be found that the friction coefficients of films would show a tendency to decrease with the hardness increasing. As the hardness of the 4-nm-period $(\mathrm{C} / \mathrm{BN}) \mathrm{n}$ film is increased at the lamination direction and the shear strength of its scratch plane is nearly similar to that of the simple layer film which has the characteristic value, it can be consider that the friction coefficient $\mu$ of the $(C / B N) n$ film is able to decrease due to its hardness increase according to the Eq. (2) when its shear strength is almost the same as that of the simple layer film. The equation shows as follows,

$$
\mu=S / H
$$

Here, $\mathrm{S}$ is a shear resistance and constant and $\mathrm{H}$ is hardness.

Figure 12 shows the section profiles of the scratch scars of all deposited films after the nanoscratch test. The maximum wear depths of the films are shown in Fig. 13. The wear scar of the 4-nm-period $(\mathrm{C} / \mathrm{BN}) \mathrm{n}$ film is the smallest. In the nanoscratch test, the destruction of the simple layer film continuously becomes degraded with gradually increasing the test load, whereas that of the superlattice film can be significantly deterred due to the restraint effect of boundary plane of the multilayer film.

Moreover, it is obvious that the maximum wear depth of the film also depends on the layer period and the wear depth of the 4-nm-period $(\mathrm{C} / \mathrm{BN}) \mathrm{n}$ film is reduced to a minimum. These results are corresponding to those of the nanoindentation hardness. Therefore, it is 
confirmed that the wear depth of the 4-nm-period $(\mathrm{C} / \mathrm{BN}) \mathrm{n}$ film decreases because its elastic modulus increases at the lamination direction.

The results of oscillating scratch test are shown in Fig. 14. The AE (acoustic emission) numbers could be obtained in this scratch test and the inclination of the scratch force curve is corresponding to the friction coefficient. As observing the curves, the inclination of the 4nm-period (C/BN)n film shows comparatively low, that is to say, the 4-nm-period (C/BN)n film has a low friction coefficient and this result is corresponding to that in the nanoscratch test and its $\mathrm{AE}$ also shows very small. When the load was rapidly increased, the AE of the 4$\mathrm{nm}$-period $(\mathrm{C} / \mathrm{BN}) \mathrm{n}$ film would increase drastically and a critical load was obtained and rather high because its surface layer destruction occurred difficultly. It became clear that the critical load of the 4-nm-period $(\mathrm{C} / \mathrm{BN}) \mathrm{n}$ film is significantly improved more than those of the simple films and other multilayer period films, and the 4-nm-period (C/BN)n film shows the high critical load and superior adhesion property.

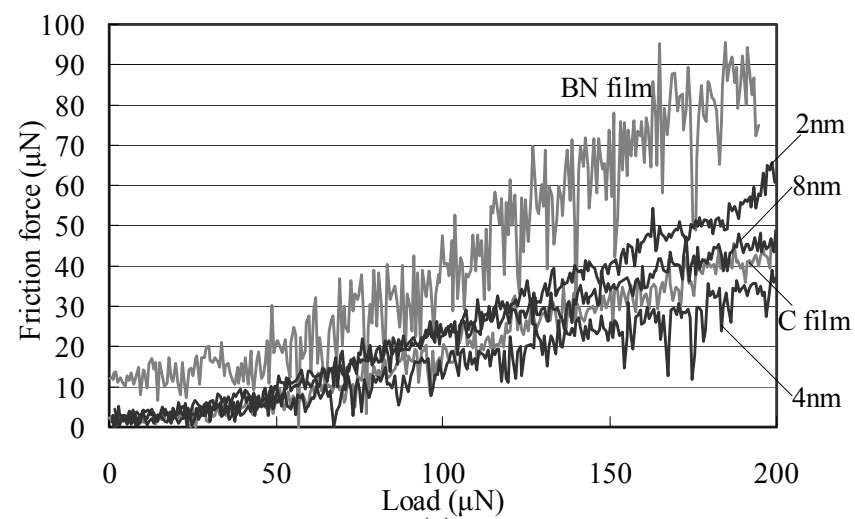

(a)

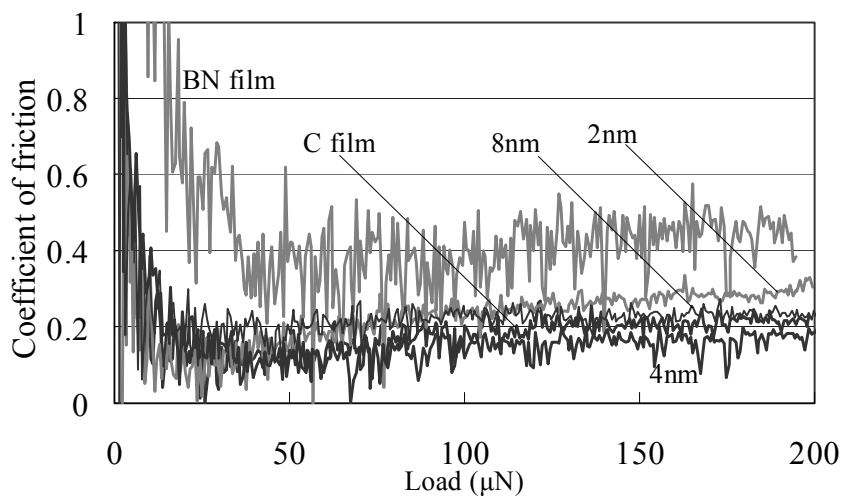

(b)

Fig. 11. Friction force (a) and coefficient of friction (b) of $C, B N$ and $(C / B N) n$ films in a load gradual increase nanoscratching test (diamond tip , load $0 \sim 200 \mu \mathrm{n}$, frictional rate $6.67 \mu \mathrm{n} / \mathrm{s}$ ) 

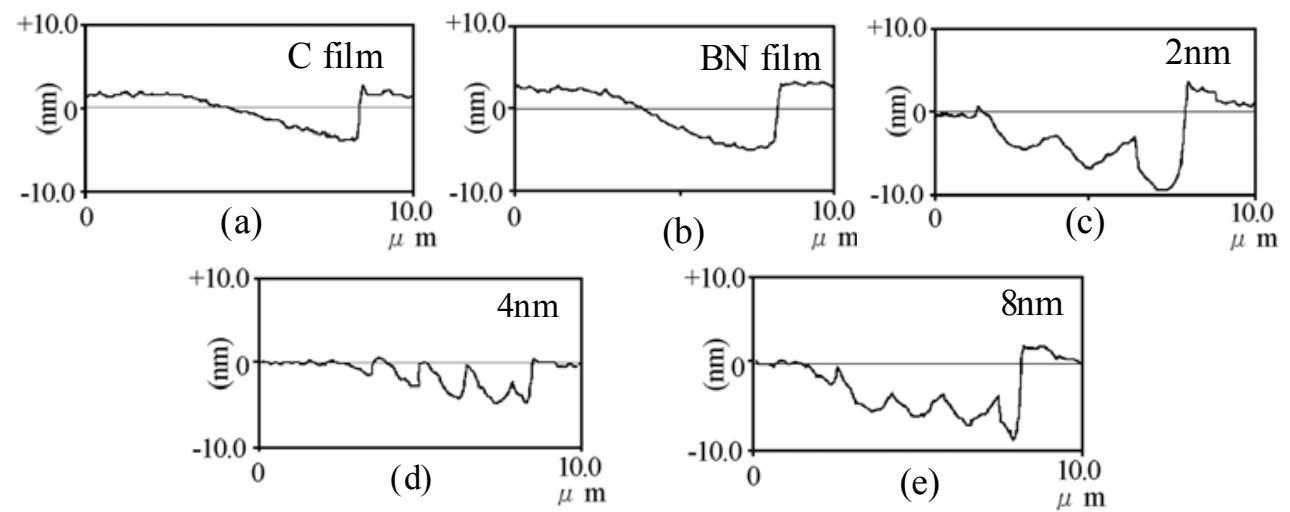

Fig. 12. Wear marks on (a) C film, (b) BN film, (c) 2-nm-period (C/BN)n, (d) 4-nm-period $(\mathrm{C} / \mathrm{BN}) \mathrm{n}$ and (e) 8-nm-period (C/BN)n film, obtained by a load gradual increase nanoscratching test

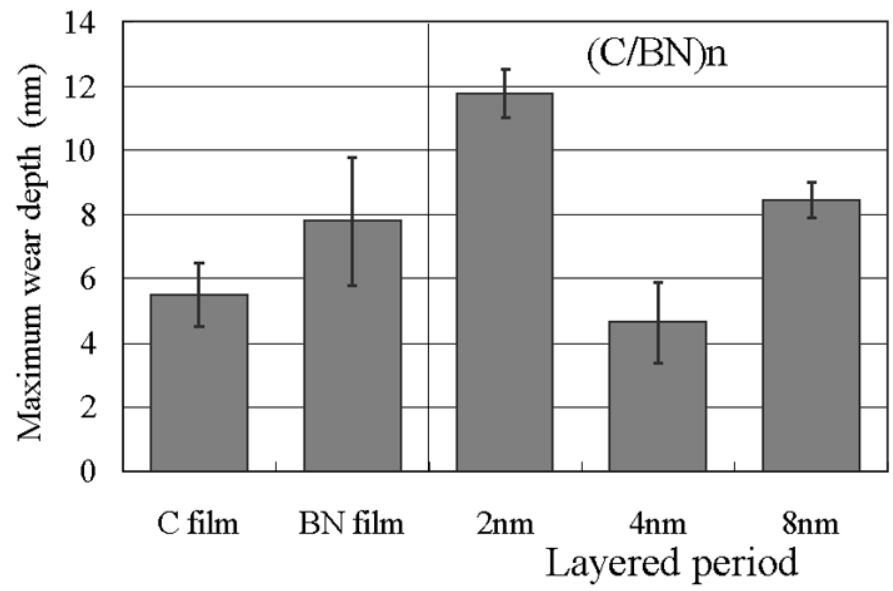

Fig. 13. Maximum wear depth by a load gradual increase nanoscratching test 


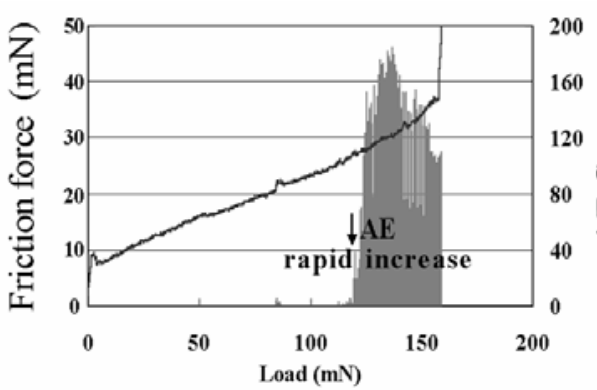

(a) C film

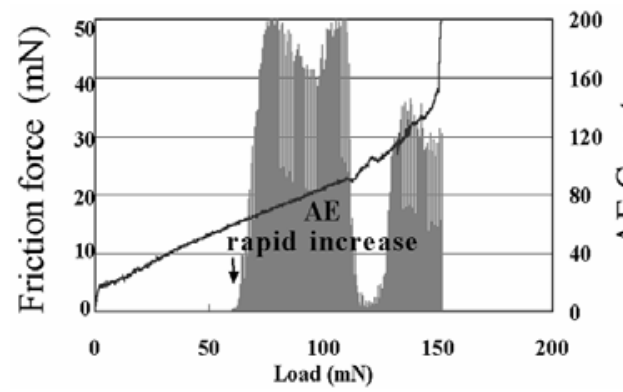

(c) 2-nm-period

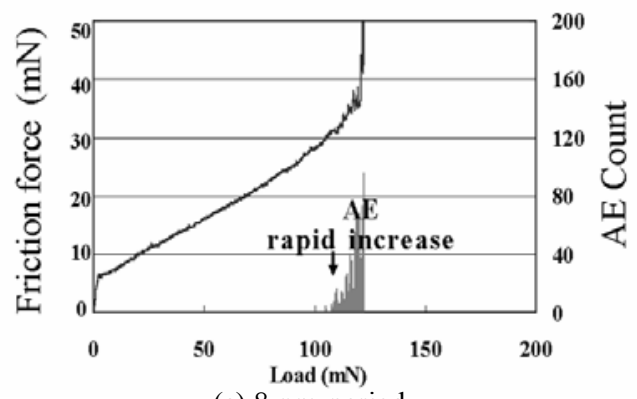

(e) 8-nm-period

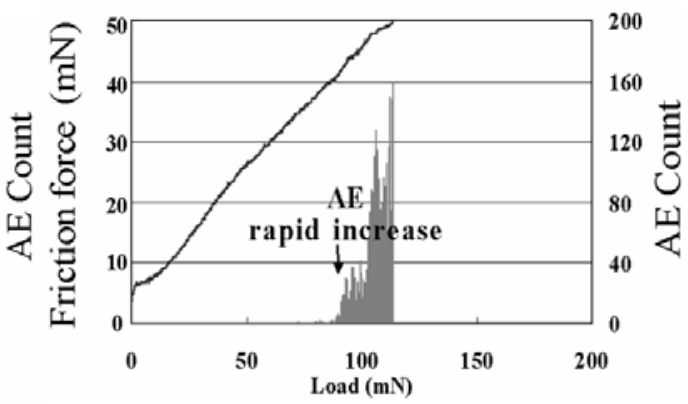

(b) BN film

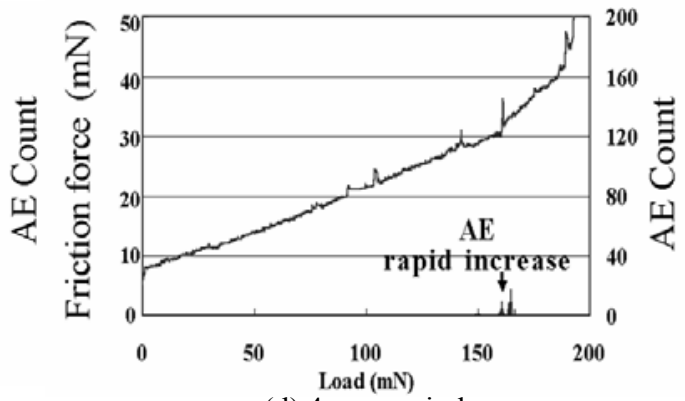

(d) 4-nm-period

Fig. 14. AE (Acoustic emission) and friction force as functions of indentation load for (a) $\mathrm{C}$ film, (b) BN film, (c) 2-nm-period (C/BN)n, (d) 4-nm-period (C/BN)n and (e) 8-nm-period $(\mathrm{C} / \mathrm{BN}) \mathrm{n}$ film, obtained by scratching test

The dependence of the friction coefficient of $\mathrm{C}$ and $\mathrm{BN}$ monolayer and $(\mathrm{C} / \mathrm{BN}) \mathrm{n}$ multilayer films on sliding cycle was investigated under a load of $9.8 \mathrm{~N}$, a sliding speed of $94 \mathrm{~mm} / \mathrm{s}$ and a room temperature of $25^{\circ} \mathrm{C}$, as shown in Fig. 15. The friction coefficient of the $\mathrm{C}$ film is $\mu=0.3$ high at sliding cycles from 0 to 1000 and sharply increased to $\mu=0.6$ at sliding cycles of 1000 and above. Corresponding to this, the friction coefficients of the 4- and 8-nm-period $(\mathrm{C} / \mathrm{BN}) \mathrm{n}$ films remain comparatively low at nearly $\mu=0.15$. Wear is hardly observed on the surface of 4- and 8-nm-period (C/BN)n films. As the surface of these films was magnified to 
observe, damage mark could be found on the 8-nm-period (C/BN)n film but not on the 4$\mathrm{nm}$-period $(\mathrm{C} / \mathrm{BN}) \mathrm{n}$ film, suggesting that the 4-nm-period $(\mathrm{C} / \mathrm{BN}) \mathrm{n}$ film has the lowest friction coefficient and superior wear resistance.

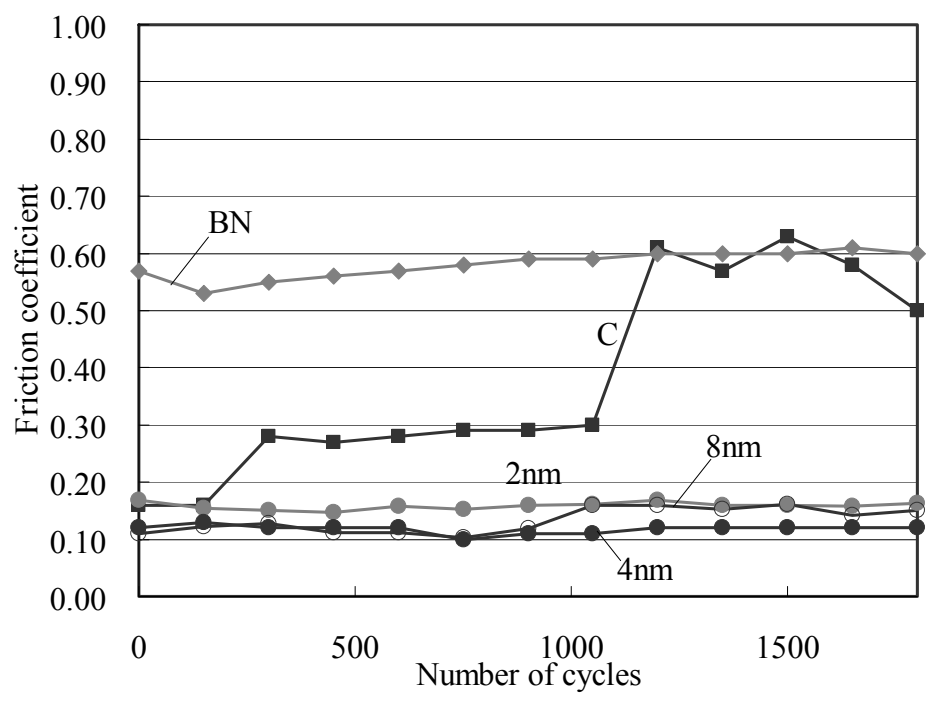

Fig. 15. Dependence of friction coefficient on the number of sliding cycles tested at $25^{\circ} \mathrm{C}$

The dependence of the friction coefficient of the nanoperiod $(\mathrm{C} / \mathrm{BN}) \mathrm{n}$ film on sliding cycles was evaluated at an environment temperature of $200^{\circ} \mathrm{C}$, as shown in Fig. 16. The friction coefficients of the $\mathrm{C}$ and BN single-layer films are high and markedly increase with sliding cycles. However, the nanoperiod multilayer films show a low friction coefficient. In particular, the friction coefficient of the 4-nm-period multilayer film is low and stable, and it is less than 0.35 after 1800 sliding cycles.

In the tribotest performed at $400{ }^{\circ} \mathrm{C}$ temperature, it is found that at sliding cycles of less than 600 , the friction coefficient of the 4-nm-period multilayer $(\mathrm{C} / \mathrm{BN}) \mathrm{n}$ is lower than that of the $\mathrm{C}, \mathrm{BN}$ and other $(\mathrm{C} / \mathrm{BN}) \mathrm{n}$ multilayer films as shown in Fig. 17. Observed the surface of the films, it is found that for the $\mathrm{C}, \mathrm{BN}$ and 2-nm-period films, the film was immediately removed by friction at the beginning of the test and the substrate was exposed, whereas the 4- and 8-nm-period multilayer films show a low friction coefficient. This result shows that the lubrication property of the multilayer films was improved due to its microstructure formed with an appropriate layer-period. The reason why the 4-nm-period multilayer film shows a longer life is considered to be as follows. For the single-layer films, the surface of the $\mathrm{C}$ or $\mathrm{BN}$ films was lubricated by the single layer during friction test. Since the $\mathrm{C}$ and $\mathrm{BN}$ single-layer films have a poor elastic deformation, i.e. a high modulus of dissipation, it was easily removed by friction test. Corresponding to this, since the multilayer film exhibits a low modulus of dissipation and defect elongation is prevented by the interface formed between layers (Miyake, 2003; Doerner \& Nix, 1986), deep plastic deformation difficultly initiate, resulting in the wear-resistance of the film being improved. The shearing damage due to friction is suppressed due to the extremely thin layer. As a result, a longer life of the surface was obtained due to the multilayer microstructure. 


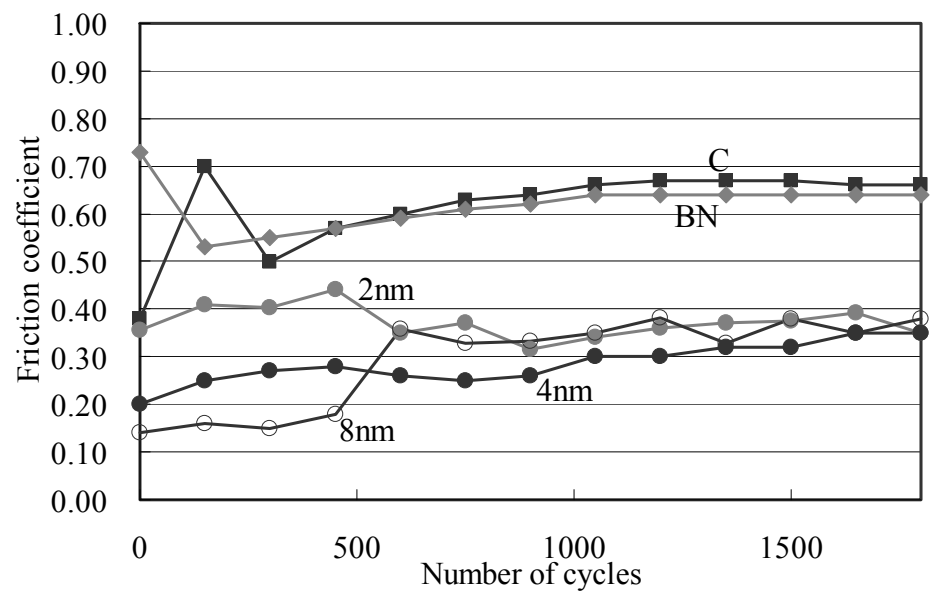

Fig. 16. Dependence of friction coefficient on the number of sliding cycles tested at $200{ }^{\circ} \mathrm{C}$

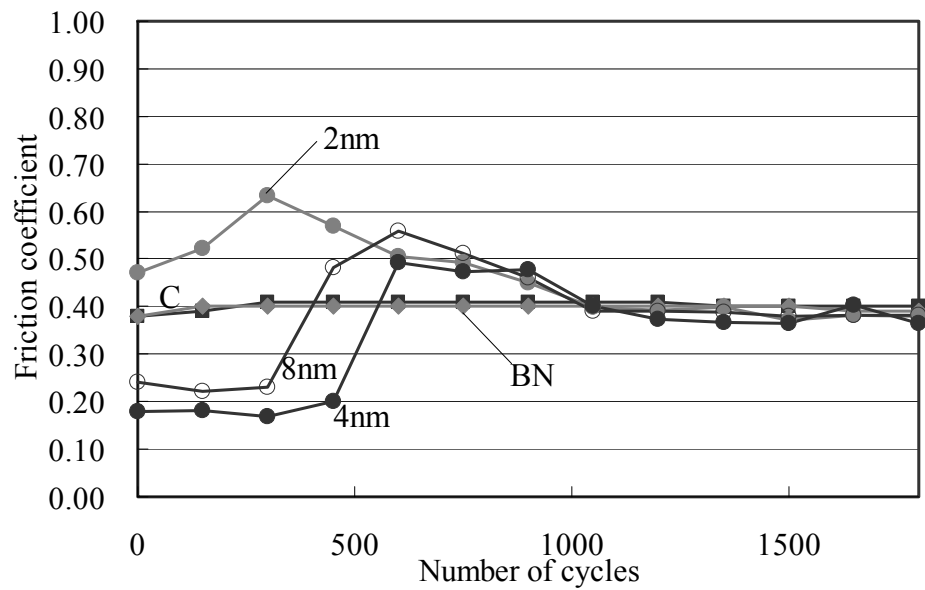

Fig. 17. Dependence of friction coefficient on the number of sliding cycles tested at $400{ }^{\circ} \mathrm{C}$

Figure 18 shows the wear profiles of $\mathrm{C}$ and BN single layers and 2-, 4- and 8-nm-period multilayers after the ball-on-disk tribotest, respectively after 1000 cycles of sliding at $25^{\circ} \mathrm{C}$. In the case of the $\mathrm{C}$ and $\mathrm{BN}$ single layers, the deep wear grooves exposed the substrate surface during sliding, producing a rough wear scar and leading to a rapid increase in the friction. Corresponding to this, the wear of the 2-, 4- and 8-nm-period (C/BN)n multilayers is very small, and therefore, after 1500 cycles of sliding, the multilayered films remained on the sliding surface and still acted as a solid lubricant to prevent wear propagation. It is considered that since the multilayer film has a low modulus of dissipation, and defect elongation was prevented by the interface between layers, such as those formed in carbon nitride and boron nitride nanomulitlayer films (Miyake, 2003), and therefore, deep plastic deformation is difficult to occur. The 4-nm-period film shows a better wear-resistance, this 
corresponds to that it has higher hardness and lower friction coefficient compared with other films in this study.

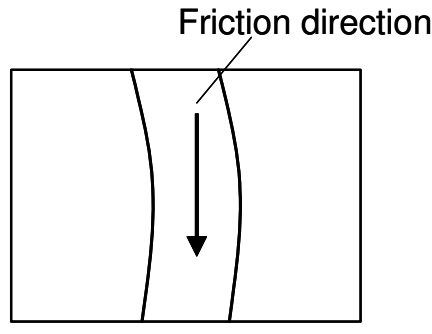

(a) Friction direction

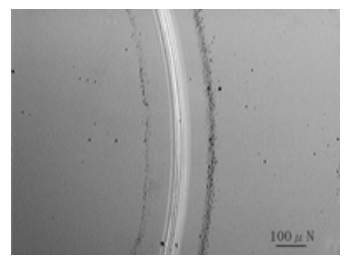

(d) $(\mathrm{C} / \mathrm{BN}) \mathrm{n} 2 \mathrm{~nm} 10 \mathrm{~N}$

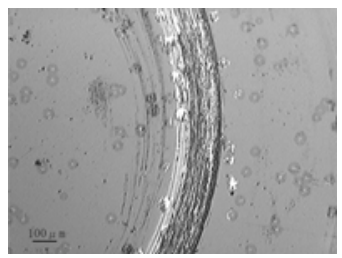

(b) C film $10 \mathrm{~N}$

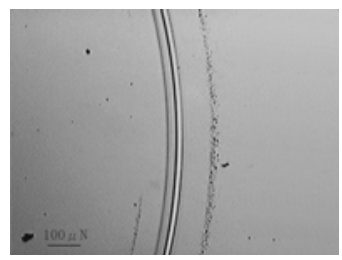

(e) $(\mathrm{C} / \mathrm{BN}) \mathrm{n} 4 \mathrm{~nm} 10 \mathrm{~N}$

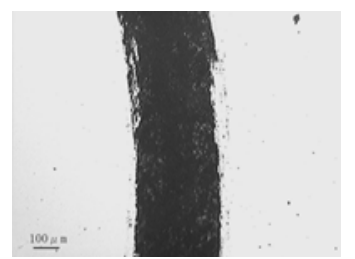

(c) BN film $10 \mathrm{~N}$

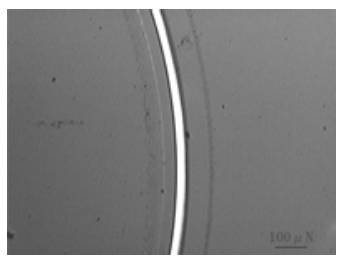

(f) $(\mathrm{C} / \mathrm{BN}) \mathrm{n} 8 \mathrm{~nm} 10 \mathrm{~N}$

Fig. 18. Microwear morphology of $C$ and $B$ single layers and $(C / B N) n$ multilayers coated on Si substrates after 1000 cycles of sliding.

\section{Conclusion}

Nanoperiod multilayer films composed of carbon and boron nitride layers, which have a structure expected to provide solid lubrication, such as the h-BN and graphite structures, were respectively deposited, and their nanoindentation and frictional properties were evaluated. The following results were obtained.

1. Micro Vickers and nanoindentaion hardness of the 4-nm-period multilayer film are the highest of all $(\mathrm{C} / \mathrm{BN}) \mathrm{n}$ films. The nanoindentation hardness of the nanoperiod $(\mathrm{C} / \mathrm{BN}) \mathrm{n}$ multilayer films changed with the layer period. A 4-nm-period multilayer film shows the highest hardness among all films in this study. It is considered that since the 4-nmperiod multilayer has the lowest modulus of dissipation and $\mathrm{E} / \mathrm{H}$, which corresponds to the ease of plastic deformation, the 4-nm-period multilayer film has mainly elastic deformation due to indentation.

2. In nanoscratch test, the friction coefficient of 4-nm-period $(\mathrm{C} / \mathrm{BN}) \mathrm{n}$ film is the lowest. As the elastic modulus increases in the laminated direction and the change of the shear resistance of sliding plane is small in the case of $4 \mathrm{~nm}$-period (C/BN)n film, therefore, its friction coefficient seems to decrease.

3. The improvement effects of 4-nm-period (C/BN)n multilayer film on the decrease of the friction coefficient and damage of the wear surface were significantly remarkable and evaluated in both of the reciprocation and ball on disk type tribo tests. 
4. The friction coefficient of the 4-nm-period (C/BN)n film was the lowest, as determined by the ball-on-disk tribotest at environment temperatures of 25,200 and $400{ }^{\circ} \mathrm{C}$. The effect of the 4-nm-period $(\mathrm{C} / \mathrm{BN}) \mathrm{n}$ multilayer film on improvement of friction coefficient and wear-resistance was experimentally confirmed.

\section{Acknowledgement}

This research was partly supported by a Grant-in-Aid to the Scientific Research Foundation from the Ministry of Education, Culture, Sports, Science and Technology (B21360076).

\section{References}

Enomoto, Y. \& Miyake, S. (1994). Tribology of thin films, Univ. of Tokyo (In Japanese), ISBN 413-061150-X, Tokyo

Miyake, S. (1999). Zero-Wear Films, J. Jpn. Soc. Mech. Eng., (in Japanese) Vol.102, No.962 (1999, 01), pp.20-24. ISSN 0021-4728

Miyake, S.; Watanabe, S.; Miyazawa, H.; Murakawa, M.; Kaneko R. \& Miyamoto T. (1994). Micro Scratch Hardness Increasing of Ion Plated Carbon Film by Nitrogen Inclusion Evaluated by Atomic Force Microscope, Appl. Phys. Lett., Vol.65, No.9 (1994) pp.3206-3208, ISSN 0003-6951

Miyake, S. (1994). Tribological improvements of polished chemically vapor deposited diamond films by fluorination, Appl. Phys. Lett., 65, 9, pp.1109-1112. ISSN 0003-6951

Miyake, S.; Watanabe, S.; Murakawa, M.; Kaneko, R. \& Miyato, T. (1992). Tribological study of cubic boron nitride film, Thin Solid Film. Vol. 212, 1-2, pp.262-266. ISSN 0040-6090

Miyake, S. \& Kaneko, R. (1992). Micro-tribological properties and potential applications of hard, lubricating coatings, Thin Solid Films, Vol. 212, pp.256-261. ISSN 0040-6090

Liu, A.Y. \& Cohen, M.L., (1989). Prediction of New Low Compressibility Solids, Science., Vol. 245, 4920, pp. 841-842. ISSN 0036-8075

Miyake, S.; Watanabe, S.; Miyazawa, H.; Murakawa, M.; Kaneko, R. \& Miyamoto, T. (1994). Improved microscratch hardness of ion - plated carbon film by nitrogen inclusion evaluated by atomic force microscope, Appl. Phys. Lett., Vol. 65, 9 (1994) pp. 32063209. ISSN 0003-6951

Li, D.; Chu, X.; Cheng, S.C.; Lin, X.W.; Dravid, V. P.; Chung, Y.W.; Wong M.S. \& Sproul W.D. (1995). Synthesis of superhard Carbon Nitride Composite Coatings, Appl. Phys. Lett. Vol. 67, pp.203-206. ISSN 0003-6951

Nakayama, A. (1997). A Mystery of Superlattice Thin Film Hardness, J. of the Jpn. Soc. of Mech. Eng., (in Japanese) Vol.100, No.943, pp.593-595. ISSN0021-4728

Miyake, S.; Sekine, Y. \& Watanabe, S. Deposition and Microtribology of Carbon Nitride and Boron Nitride Super Lattice Films, (1999). Trans. Jpn. Soc. Mech. Eng., (in Japanese) Vol.65, No.639, C pp. 4496-4501. ISSN 0287-7066

Donohue, L.A.; Cawley, J.; Lewis, D.B.; Brooks, J.S. \& Munz, W.D. (1995). Investigation of superlattice coatings deposited by a combined steered are evaporation and unbalanced magnetron sputtering technique, Surf. Coat. Technol. Vol 76-77, pp.149158. ISSN 0257-8972

Miyake, S. \& Sekine, Y. (2000). Improvement of Tribological Properties of Carbon Films due to Other Material Addition, Proc. of Int. Tribol. Conf., Nagasaki, 2000, pp.59-64. 
Miyake, S. (2003). Improvement of mechanical properties of nanometer period multilayer films at interfaces of each layer, J. of Vac. Sci. E Technol. Vol. 21B, 2, pp.785-790. ISSN 0734-211X

Bowden, F.P.; Moore, A.J.W. \& Tabor, D. (1943). The Ploughing and Adhesion of Sliding Metals, J. Appl. Phys. Vol. 14, 2, pp.80-92. ISSN 0021-8979

Miyake, S; Sekine, Y.; Noshiro, J. \& Watanabe, S. (2004). Low-Friction and Long-Life Solid Lubricant Films Structured of Nanoperiod Tungsten Disulfide and Molybdenum Disulfide Multilayer, Jpn. J. Appl. Phys., Vol. 43, 7A, pp.4338-4343. ISSN 0021-4922

Miyake, S.; Sekine, Y. \& Watanabe, S. (2004). Low friction model of nanoperiod multilayer solid film: as the shearing strength $S$ is constant, $\mu$ decreases with an increase in hardness, Jpn. Soc. Mech. Eng. Int. J. Vol. 47C, 1, pp.377. ISSN 0021-4728

Doerner, M.F. \& Nix, W.D. (1986). A method for interpreting the data from depth-sensing indentation instruments, J. Mater. Res. Vol. 1, 4, pp.601-609. ISSN 0272-9172

Miyake, S. (2005). Tribology of carbon nitride and boron nitride nanoperiod multilayer films and its application to nanoscale processing, Thin Solid Films, Vol. 493, 1-2, pp.160169. ISSN 0040-6090

Syed Asif, S.A.; Wahl, K.J. \& Colton, R.J. (1999). Nanoindentation and contact stiffness measurement using force modulation with a capacitive load-displacement transducer, Rev. Sci. Instrum. Vol. 70, 5, pp.2408-2414. ISSN 0034-6748

Miyake, S. \& Kim, J. (2003). Nanoprocessing of Carbon and Boron Nitride Nanoperiod Multilayer Films, Jpn. J. Appl. Phys. Vol. 42, 3B, pp.L322-325. ISSN 0021-4922

Miyake, S.; Sekine, Y.; Kim, J. \& Yamamoto, H. (2000). Development of Nanofabrication Technique Based on Wear Properties of Nanoperiod Multilayerd Films, (in Japanese), Journal of the Japan Society of Precision Engineering., Vol. 66, 12, pp.19581962. ISSN 0912-0289

Taniguchi, N. (Ed.), (1996). Nanotechnology: Integrated Processing Systems for Ultra-Precision and Ultra-Fine Products, Oxford Univ Pr on Demand, ISBN-10 0198562837, Oxford Science Publications

Bhushan, B. (Ed.), (1995). Handbook of Micro/Nanotribology, CRC Press, Inc., ISBN 0-84938401-X, USA 


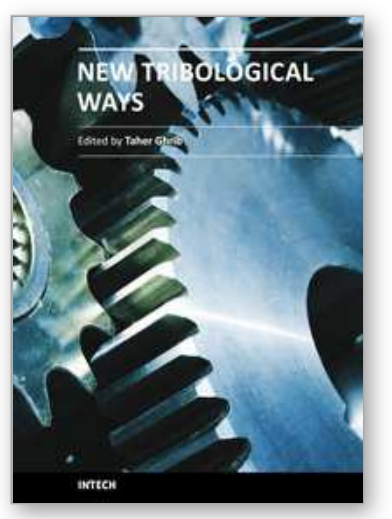

\author{
New Tribological Ways \\ Edited by Dr. Taher Ghrib
}

ISBN 978-953-307-206-7

Hard cover, 498 pages

Publisher InTech

Published online 26, April, 2011

Published in print edition April, 2011

This book aims to recapitulate old information's available and brings new information's that are with the fashion research on an atomic and nanometric scale in various fields by introducing several mathematical models to measure some parameters characterizing metals like the hydrodynamic elasticity coefficient, hardness, lubricant viscosity, viscosity coefficient, tensile strength .... It uses new measurement techniques very developed and nondestructive. Its principal distinctions of the other books, that it brings practical manners to model and to optimize the cutting process using various parameters and different techniques, namely, using water of high-velocity stream, tool with different form and radius, the cutting temperature effect, that can be measured with sufficient accuracy not only at a research lab and also with a theoretical forecast. This book aspire to minimize and eliminate the losses resulting from surfaces friction and wear which leads to a greater machining efficiency and to a better execution, fewer breakdowns and a significant saving. A great part is devoted to lubrication, of which the goal is to find the famous techniques using solid and liquid lubricant films applied for giving super low friction coefficients and improving the lubricant properties on surfaces.

\title{
How to reference
}

In order to correctly reference this scholarly work, feel free to copy and paste the following:

Shojiro Miyake and Mei Wang (2011). Deposition and Tribology of Carbon and Boron Nitride Nanoperiod Multilayer Hard and Solid Lubricating Films, New Tribological Ways, Dr. Taher Ghrib (Ed.), ISBN: 978-953307-206-7, InTech, Available from: http://www.intechopen.com/books/new-tribological-ways/deposition-andtribology-of-carbon-and-boron-nitride-nanoperiod-multilayer-hard-and-solid-lubricatin

\section{INTECH}

open science | open minds

\section{InTech Europe}

University Campus STeP Ri

Slavka Krautzeka 83/A

51000 Rijeka, Croatia

Phone: +385 (51) 770447

Fax: +385 (51) 686166

www.intechopen.com

\section{InTech China}

Unit 405, Office Block, Hotel Equatorial Shanghai

No.65, Yan An Road (West), Shanghai, 200040, China 中国上海市延安西路65号上海国际贵都大饭店办公楼 405 单元

Phone: +86-21-62489820

Fax: $+86-21-62489821$ 
(C) 2011 The Author(s). Licensee IntechOpen. This chapter is distributed under the terms of the Creative Commons Attribution-NonCommercialShareAlike-3.0 License, which permits use, distribution and reproduction for non-commercial purposes, provided the original is properly cited and derivative works building on this content are distributed under the same license. 